\title{
Humans and viticulture in Sardinia: The history and social relations as signs of identity of the wine-growing area
}

\author{
Graziella Benedetto $^{1, \mathrm{a}}$, Donatella Carboni ${ }^{2, \mathrm{~b}}$ and Gian Luigi Corinto ${ }^{3, \mathrm{c}}$ \\ ${ }^{1}$ Dept. of Science for Nature and Environmental Resources, University of Sassari, via E De Nicola, 07100, Italy \\ 2 Dept. of Human and Social Science, University of Sassari, via Roma, Italy \\ ${ }^{3}$ Dept. of Education, Cultural Heritage and Tourism, University of Macerata, P.le Bertelli, 1, 62100 Macerata, Italy
}

\begin{abstract}
The premise of this paper is that viticulture is an expression of history and social relations. In this sense, we embrace a post-modern vision of development that characterized both economic and cultural geography and agricultural economics. Such an approach does consider culture as an element of mediation between humans and the nature, placing it at the heart of the wine-growing territory. So history and social relations have influenced the today spatial densification by types of grape and the persistence, the reduction and/or disappearance of vines' cultivations due to the different level of integration between humans and wine territories in the Italian region of Sardinia. In this region, there are selected areas where winegrowers have been forced to grub vineyards up, depleting the regional viticultural heritage, others-within which the fabric of the system of social relationships were denser-and where we saw a real rush to purchase of replanting rights for the expansion of the production surface for the increasing of production. The aim of this paper is to highlight the role of history and social relations in the determination of the structure of the regional viticulture through the identification and analysis of diverse case studies.
\end{abstract}

\section{Introduction}

The premise of this paper is that viticulture is an expression of history and social relations. In this sense, we embrace a post-modern vision of development that characterized both economic and cultural geography and agricultural economics. Such an approach does consider culture as a mediator between humans and the nature, putting it at the heart of a wine-growing territory.

Pedo-climatic and the geographical locations have always represented an important determinant for the wine business in Sardinia. The spreading of the vines is also related to the historical period and the particular civilizations that planted them. That is why it was so diversified in the island.

The spatial variable concentration of vineyards by type of grape, persistence, the area reduction and/or ceasing of wine-growing are deeply influenced by the social relations that produced the different level of integration between humans and the territory [1]. There, for example, are areas where entrepreneurs have been forced to grub vineyards up, depleting the regional viticultural heritage, and other areas in which the social fabric of the relationship system was denser, and where, conversely, a rush to purchase "vineyard replanting rights" took place, in view

\footnotetext{
a e-mail: gbenedet@uniss.it

b e-mail: carbonid@uniss.it

c e-mail: gianluigi.corinto@unimc.it
}

of improving the production surface and increasing the grape produce $[2,3]$.

The reduction of cultivated areas, as well as the ceasing of some Cooperative Wineries affected in different ways the wine-growing economy of Sardinia just due to the different degree of integration of winemaking in the local economies. That integration is closely associated with the degree of social cohesion of the producing community, the diffusion of collaborative practices and associations, the social capital and the capacity of institutions to influence and guiding the development paths of the regional winemaking sector [4].

The vineyard area has decreased from about 70,000 hectares, in the seventies and eighties, to an average of 38,000 hectares in the early 2000s [4]. From 2006 to 2010, the vineyard surface further decreased by more than the $10 \%$ [4]. Nuoro is the province that has most reduced its wine heritage $(-21 \%)$. There are discrepancies between data furnish by ISTAT (Italian National Statistical Service) and AGEA (National Agency for Funding Agriculture), as stated by Laore (Sardinian Agency for Regional Programs) in 2010 that surveyed only about 26 thousand hectares. Still examining this difference, and using both sources we can state viticulture has its highest concentration in the province of Cagliari (about 35\% of the regional wine heritage).

The thematic map (Fig. 1) highlights the areas with the highest concentration of vineyards at the municipal scale, using the data AGEA furnished in 2010. The viticulture 


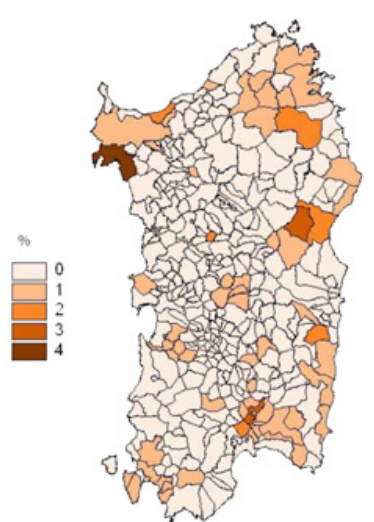

Figure 1. Incidence of a viticulture surface by municipality.

is widespread throughout the region, besides a few areas in which it is completely lacking (for example, Sedilo, Milis, Soddi, Tadasuni or Zerfaliu) or does not even reach the $0.05 \%$ of the regional vineyard surface (for example Castelsardo, Stintino, Nulvi, Nule and others). The hillside is still the altimetric area where the regional viticulture is denser [5]. The average vineyard area is lower than 1 hectare and the smallest size of viticulture is more typical of the mountain than the plain [5].

Municipalities with a high vineyard density are not very numerous. In the province of Sassari, Alghero clearly stands at $3.64 \%$ of the total regional area, then Sorso (2.09\%), Monti (1.84\%), Berchidda (1.30\%), Badesi $(1.23 \%)$ and Calangianus $(1.20 \%)$. In the province of Cagliari, Serdiana (2.77\%) is significant, then Sestu $(1.44 \%)$, Ussana (1.44\%), Giba (1.14\%) and Muravera $(1.03 \%)$. In the province of Nuoro the highest density of vines is detected in Oliena (2.66\%), then Dorgali (1.99\%), Jerzu (1.69\%), Tertenia (1.23\%) and Mamoiada (1.02\%). In the province of Oristano, only Mogoro has more than the $1 \%$ of the regional vineyard area.

Using data of ISTAT and AGEA, we can compare the above mentioned thematic map to that of the diffusion of the main grape types cultivated in the region, considering also the location areas, to be linked to the history of the introduction of wine-growing in Sardinia.

Varietal asset of wine grapes in Sardinia consists of 64 grape types. Some are very famous and largely diffused all over the region. Others-so called minors-play a secondary role and are eventually in danger of dismissing. As already said, notwithstanding this extraordinary degree of variability, very few the varietals are still used in the entire regional territory $[4,6]$. In 2010, the ampelographic base of Sardinia is composed by the $69 \%$ with only 5 grapes: Cannonau nero (29\%), Vermentino bianco (17\%), Carignano nero (9\%), Monica nero (7\%) and Nuragus bianco (7\%) [5]. Share of autochthonous grapes is largely bigger than international ones, such as the Sangiovese and Trebbiano, planted during the thirties in Sardinia in the reclamation zone of Arborea. The red grapes are more than the white ones, with about $61 \%$ and $39 \%$ of the total surface respectively. This proportion is typical also for the province of Sassari, is quite bigger in the province of Nuoro, and is nearly the same in the provinces of Cagliari and Oristano.
Considering the qualitative profile, we can state more than half of the Sardinian vineyards produces AOC and GAOC grapes. Still, Cannonau (35\% of the certified area) and Vermentino (28\%) are the main important grapes in the regional framework, while Carignano nero (10\%), Monica nero and Nuragus bianco (both with 5\%) are clearly less diffused. Certified grapes are concentrated in the province of Cagliari (34\%), followed by Sassari (34\%) and Nuoro $(24 \%)$.

We can classify the Sardinian provinces by means of the varietal density and the spatial diffusion of grape types, and yet identify some homogeneous areas. In the province of Cagliari, the main wine areas are laid in the agrarian zones of "Campidano of Serrenti" (Serdiana, Ussana), "Campidano of Cagliari" (Sestu, Selargius, Settimo San Pietro), the "littoral hills of Capo Ferrato" (Muravera, Villaputzu), the "littoral hills of Sulcis" (Sant'Anna Arresi, San Giovanni Suergiu) and the "littoral hills of Capo Carbonara" (Maracalagonis). I this province the most used grape type is Nuragus, followed by Monica, Carignano, which is typical of the Sulcis, and Cannonao.

In the province of Nuoro, the main part of vineyards are laid in the agrarian zone of the "hills of Nuoro" (Oliena), the "littoral hills of Dorgali" (Dorgali), the "littoral hills of Ogliastra" (Jerzu, Tertenia, Gairo), the "Western Gennargentu" (Mamoiada), the "Eastern Gennargentu" (Orgosolo), and the "Mandrolisai and Eastern Barbagia" (Ortueri). In these zones the Cannonao can be certainly considered as an expression of the local culture [7]: this grape prevails over others in all the municipalities, both in very specialized areas (Oliena, Dorgali, Jerzu, Tertenia, Mamoiada) and in the minor areas (such as Gairo or Irgoli) where the Cannonao is more than the $97 \%$ of cultivated grapes. Even in some municipalities with very low winegrowing density (Gavoi, Loceri, Lotzorai, Olzai), the cultivation is clearly mono-varietal.

In the province of Oristano, the agrarian zone with the main vineyard area is the "Campidano of Oristano" (Mogoro, Marrubiu, Riola Sardo, San Nicolo d'Arcidano, Terralba and Uras). This is a zone of ancient traditions and the wine more emblematic is the "Vernaccia of Oristano".

In the province of Sassari, the agrarian zones with vine-growing activities are "Pianura of Sassari", within which there is the municipality of Alghero, at the first position, having the $1 \%$ of the regional vineyard area. Here, the principal grape type is the Vermentino $(31 \%$ of the municipal wine area), then the Cannonao (19\%) and Torbato $(15 \%)$. In the same agrarian zone, the municipalities with wine-growing area Sorso, Sassari (Vermentino 35\%, Cannonao, 20\%, and Cagnulari, 7\%), Usini (Vermentino 94\%) and Tissi (Cannonao 47\% and Cagnulari 3\%)

A further interesting agrarian zone is that of the "hill of high Coghinas" (Monti, Berchidda, Calangianus, Luras and Telti), besides the "littoral hills of western Gallura" (Badesi, Tempio) an "eastern Gallura" (Olbia and Arzachena), which is better known as "Gallura". In this zone, grape type of territorial identity is the "Vermentino of Gallura", the sole GAOC in Sardinia.

After these general descriptions, the following parts of the paper will treat the spatial identities of main wine 


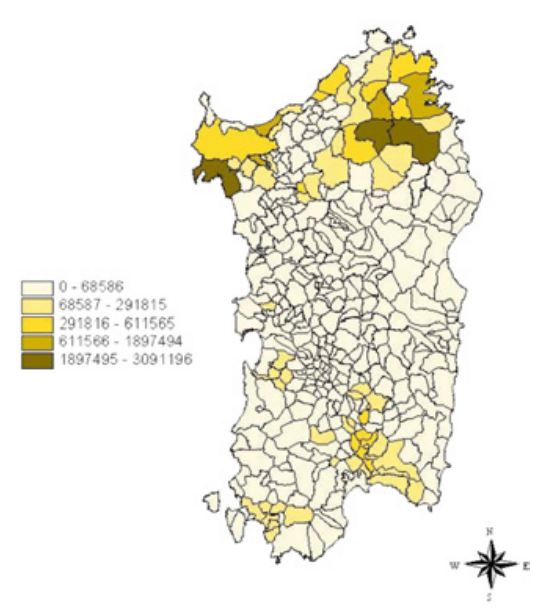

Figure 2. Distribution of Vermentino surface in Sardinia.

areas (i.e. municipalities or group of municipalities where the density of vine-growing is higher than the rest of the region), focusing on the two main regional grapes, the Vermentino and the Cannonao.

The sign of identity we considered is be the wine landscape, to be assessed as the landmark of history and the local producing community $[7,8]$.

Sardinia still has a great heritage of rural landscapes, which have been built over millennia and inseparable from traditional cultivating practices which originated diverse complex systems in relation to locally variable conditions. In these variable zones, diverse types of grape have been selected and adapted, originating identity-wines typical of different zones.

The "vine roots" are even the symbol of the adhesion and allegiance to the territory and history. The symbiotic relation humans-vine is still the origin of a more complex mix made of habitat, culture, society, history, ancestral knowledge, vicissitude of land property and the overall economy.

\section{The case of Vermentino}

Following scholars [9], the Vermentino has an uncertain origin, and coming from Spain (Listan in Andalusia), after the preceding spread in France (Grosse Clarette, Malvoisie d'Espagne, Piccabon), in Liguria (Pizzamosca, Corbesso, Vermettino), in Corse (Vermentino) then reached the Gallura at the end of the sec. XIII [9]. Today, the most part of Italian areas planted with Vermentino is located in Sardinia [10], and AGEA still accounted for 2900 hectares in 2010. The Fig. 2 shows the principal zone of localizations, mainly near the sea coasts. Fregoni [11] individuated three localizing determinants: sea, stone and light, and indeed three are the subsequent colors, yellow as the sun, red as the stone and blue as the sea. Geographically, areas with Vermentino are situated both in the Northern and in the Southern Sardinia. In the north, it lays in the littoral hills of the western Gallura and in the plains of Sassari. In the north, it lays in the littoral hills of Sulcis, Iglesias and of Capo Ferrato, besides the Campidanos of Cagliari and Serrenti.

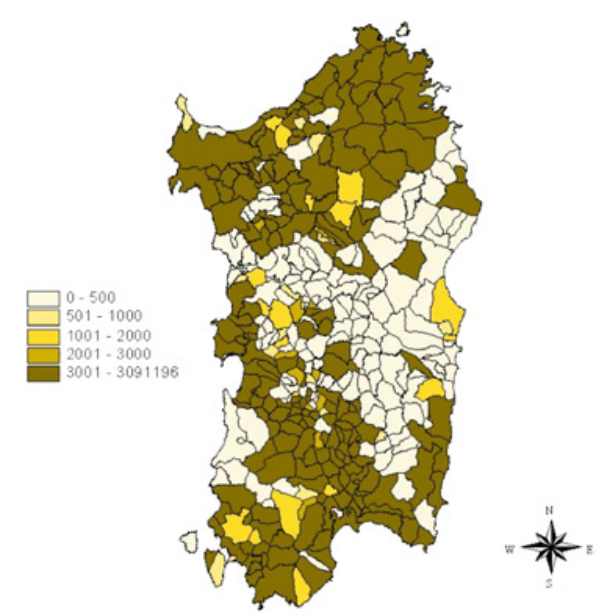

Figure 3. Distribution of Vermentino by minor areas.

We can distinguish two homogeneous zones, one of the GAOC Vermentino of Gallura and the second one of the AOC Sardinian Vermentino. The former has a larger diffusion in municipalities catalogued by the GAOC protocol and located in the province of Sassari, besides Budoni and San Teodoro that are located within the province of Nuoro. The main municipalities are Monti with about the $11 \%$ of the total Sardinian area with Vermentino, Berchidda (about 8\%), Calangianus (about $7 \%$ ), Arzachena (more than 2\%), Telti (about 2\%), Oschiri, Luras and Badesi (about 1,6\%).

Outside the production area of Vermentino of Gallura, the "white" grape is cultivated (only a minor part is black colored) which has its main location in the municipality of Alghero (more than 10\%), in those of Sorso and Usini (more the 4\%), Olbia (about 5\%), where singular and cooperative processing significant units are located and even well known at the national level. With respect to the second type, the Santa Maria La Palma and the SorsoSennori cooperative wineries. In the province of Cagliari, the municipalities of Senorbì (about 2\% of the regional area), Ussana (1,53\%), Serdiana and Settimo San Pietro (about $1,20 \%)$, and Santadi $(1,02 \%)$ have big and famous private processing units, well known even at the national level.

We have drawn the Fig. 3 in order to enucleate the geographical location at the municipal level also for the "minor areas". In fact, it could be intriguing to describe the "domestic character" of Vermentino, besides the obvious regional importance and large diffusion.

Considering the foremost productive areas, the vine-growing landscape of Vermentino is largely diversified. This is related to the geo-environmental local characters, the site specific culture, and cross industry relations (viticulture-wine processing-distribution) which took place over time.

In the zone of Gallura vine-growing was-and still is-a specialized activity. Indeed, for example, in Monti vineyards are bordered by fruit trees, while in many other regional areas the vine have been combined with olive oil tree in the same ground. Moreover, the vineyard is surrounded by dry-stone walls or bushed fence.

The viticultural landscape characterizing the Gallura is very diversified. In the western zone you can see small 


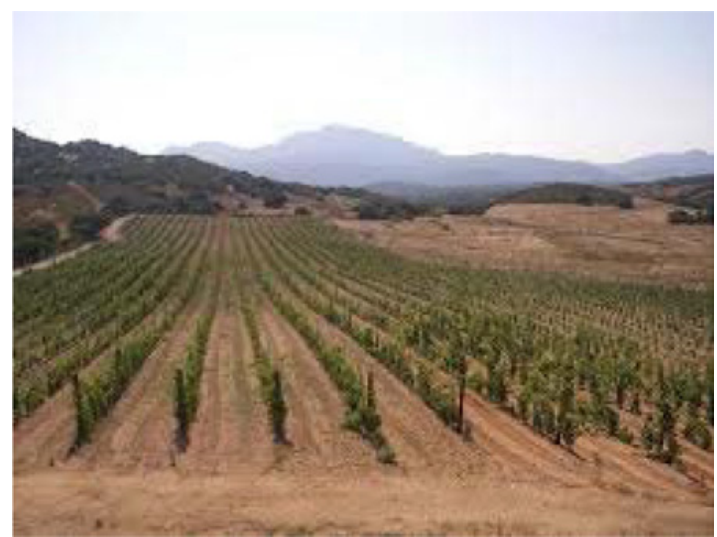

Figure 4. Wine landscape in Gallura, municipality of Arzachena.

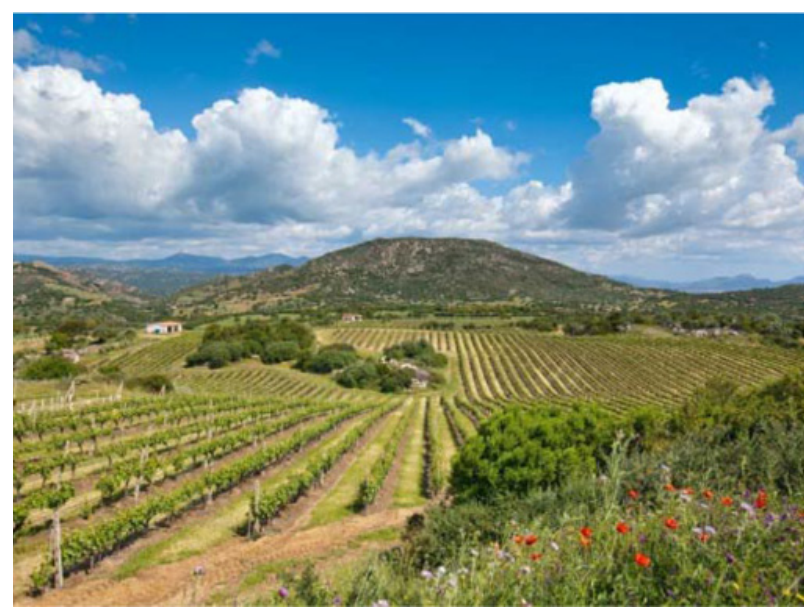

Figure 5. Wine landscape in Gallura, near the Limbara Mount.

vineyards, adopting the traditional "small tree" forms, and big specialized areas actually managed with modern techniques, cultivated in counter planting with a medium density. In the central and eastern zones, the vineyards are located in the hilly countryside dense of woods and mediterranean maquis.

The municipality of Monti, in Gallura, played a fundament role in the development of the wine processing, yet originating the industrial production of Vermentino. Besides the diffusion of Sughereto (cork woods), the cultivation of figs and vine were the sole possible farming opportunity. Initially, the vineyards pertained to the wealthy class, then even common people became winegrowers, seeing the goal to become industrial producers in a large scale [9].

Mass quantities of grapes were initially delivered to the private wineries of Cagliari and Sassari. In 1956 the "Monti and Telti Vermentino cooperative winery" has been founded, lacerated in Monti and today named "Monti cooperative winery". Still in Gallura, there are other wine processing companies, both cooperative (Berchidda and Tempio cooperative winery) and private ones. A past deep study [7] underlined the enterprises producing Vermentino of Gallura are actually historical units. There are three cooperative wineries, lasting from the mid-fifties, while the most part of companies has more than ten years of activity, with a large selling success of the Vermentino.
Noticeable is that the business starting-up has been strictly connected to the familiar network, Young entrepreneurs, having inherited the familiar company, then modified not only the name but furthermore the organization and even the vision of the company. In some cases, they introduced the bottling, in others changed from the selling to processing units to self managing the all production chain. The success of thus type of wine is surely due to the development of tourism in the Costa Smeralda, where they can deliver the major part of the production. In Italy, the principal markets are the Center-north, and exportations are shipped in exigent and selective destinations such as Japan, the Great Britain and Germany [7].

In the agraria region of the plain of Sassari, within which there are the municipalities of Alghero, Sassari, Olmedo, Sorso, Tissi, Uri and Usini, the viticulture has very ancient roots, attested by remains of greek wine pots and jars of the XIV BC century. The diffusion, in this area, of many ancient wine laws, still continuing today, testify a long lasting winemaking tradition $[11,12]$. In this vast agricultural zone the wine landscape shows a great variability due to diverse functions that vine-growing can afford. In the municipality of Alghero, it has a clear economic function. There are two big production units, the Santa Maria La Palma cooperative winery, the ranks the first region position for quantity of processed grapes and the Sella \& Mosca company, which is an integrated big unit, positioned among the principal european producers. In a minor scale, also the viticulture of Sorso and Usini has a clear economic function. Here, there are a cooperative winery and a private wine entrepreneur, the Cherchi company. In Usini, Uri and Tissi, vine-growing performs also a social function, with characteristics completely diverse than those in Alghero. The selling of wine in bulk is still largely diffused, even in small domestic cellars located within the town itself. The spur cordon and the free mobile took place over the canopied vineyards. Viticulture is a specialized activity.

The the agrarian zones of Campidano of Cagliari and Serrenti, the landscape shows a combination between vines and olive tree included in cultivations of both intensive and estensive herbaceous and forage crops, manly along the costal hills. In the inner zones the land covering by vineyards is denser. Traditional training forms are residual, limited to few farms, denoting the modernization of local viticulture in big specialized areas. The guyot and spur cordon are the mainly adopted systems of training. 1s grounds stands alternates cordon prevailing system.

\section{The case of Cannonao}

The Cannonao is a grape surely originated in Spain, similar to the Siviglia Canonazo, the Aragon Granaxa and the French, which found in Sardinia the best pedo-climatic conditions.

During the Aragon and Spain dominations, many Spanish grapes have been introduced in Sardinia, including the white Cannonao (Camedda) and the proper red Cannonao [9].

In 1612 the delegate of King Philip I, Martin Carrillo, wrote: "There is in Sardinia a very good wine. They 


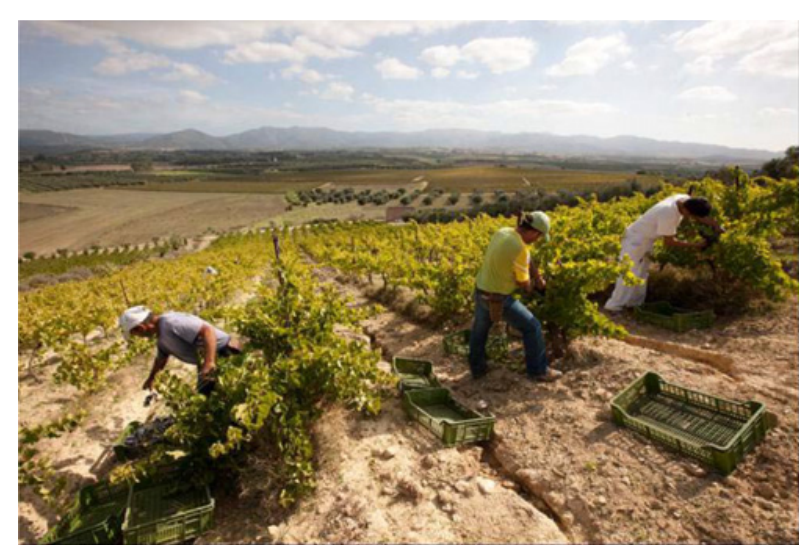

Figure 6. Wine landscape in the municipality of Serdiana.



Figure 7. Distribution of Cannonao surface in Sardinia.

continue to plant vines and produce a lot of wine in the Reign of Sardinia [...] the are red and white wines. The Cannonau has e ruby color and is safe and tasty." Cultivation of this grape stabilized over time in selected areas, traditionally considered good for farming, and building well functioning precesses in combination with social relations and good institutions produced the territorial economic force, contributing to the entrepreneurial motivations for development. For this, the Cannonao is both the most renown Sardinian win' and the wine for Sardinians.

The Cannonao grape is spread in all the Sardinian territory, but it is a real landmark in the province of Nuoro. In this province, there is the $70 \%$ of the total regional area of Cannonao (Fig. 7).

Main areas are the municipalities of Oliena $(9 \%$ of the total regional area), Jerzu (6\%), Dorgali (about $7 \%$ ), Mamoiada and Tertenia (around 4\%), Orgosolo and Siniscola (around 3\%). In these mentioned municipalities and even in minor others, the Cannonao grape is the main one. In the municipality of Jerzu it reaches up to the $97 \%$ of grapes. In Dorgali Cannonao and Sangiovese do prevail, in Oliena they have only Cannonao, as wells in many other petty municipalities, such as Lanusei, Irgoli, Gavoi and Gairo, where the terraced landscape is largely diffused.

The province of Sassari has more than the $15 \%$ of the Cannonao regional area, and in particular Sorso (more

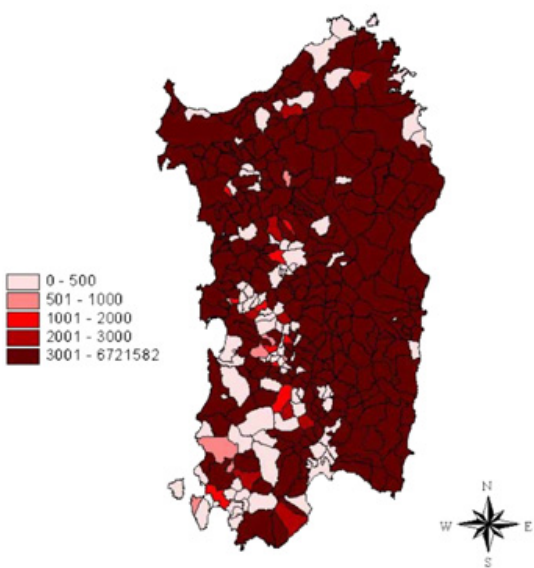

Figure 8. Distribution of Cannonao by minor areas.

than 3\%), Alghero and Badesi (about 3\%). The province of Cagliari has the $13 \%$ of the regional Cannonao area, and the principal municipalities are Muravera and Busachi (nearly 2\%), Villaputzu (1.45\%), San Vito, Serdiana and Villasanta (near 1\%).

The province of Oristano has the minor extension of the vineyard with Cannonao grape. The municipality of Allai has the smallest area with only 400 square meters. Others, such as Ittireddu (Sassari), Villaverde, Baradili San Pietro, Morgongiori (Oristano), Iglesias and Calasetta (Cagliari) have areas between 501 and 1000 square meters (Fig. 8).

Characteristics of wine Cannonao vary along with the production zones. It can grow with no distinct pedoclimatic exigencies, and indeed it is diffused in all the island, well thriving both in the extreme south (Sarrabus and Gerrei) and in the extreme north (Romangia). Even altitude is not an issue. In the province of Nuoro the Cannonao can grow even at more than 700 meters s.l.m.

It is the emblematic mountain Sardinian grape, performing economic and social functions. The regional agency Laore programmed a sustainable vine-growing managing, capable of assuring fair farm revenues, the conservation of biodiversity of grapes, soils and landscapes.

Furthermore, from many years Laore programmed the zoning of viticulture, with a sound and detailed knowledge of the territory, and weak and strong points of environmental geology. Future programs will provide an experimental plan for natural engineering of vineyards in a sample zone. The interested area is much geologically vulnerable, and lays in the mountain hydrological subbasin of the AOC territory of Cannonao in Jerzu.

It is noticeable, aim to identify a "Jerzu biotype" of Cannonao, starting from residual ancient vineyards. This study enlightened some peculiar differences with respect to usually utilized grape-type clones. New genotypes can help on the safe of local biotypes and the production of strongly territorialized wines.

The development of linkages between terroir, history, culture and grape-types is to be considered an actual foster issue for the mountain zones. The Cannonao grape shows a minimal adaptability to those soils which are capable 


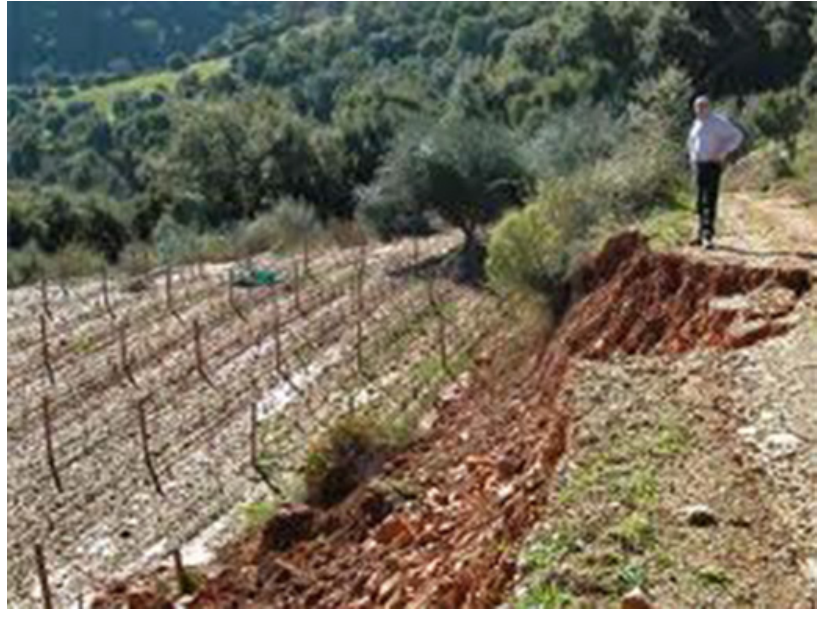

Figure 9. Mountain wine landscape.

of strongly influence the wine characteristics. Vitagliano stated the best soils are those produced by the granite terrain, littoral sandy soils, and in general with low organic substance and rich in potassium.

The schist soils, the deep fertile alluvial soils are the worst, even if rich in potassium. In those soils, the wine is without good qualities and a little better is the wine from calcareous soils. The Cannonao grape doesn't prefer wet soils and with a high groundwater.

The Cannonao grape is cultivated in the small Latin tree shape, and the new plantations vine-grovers prefer the Guyot and the spur cordon.

This grape-type is used to produce homonymous AOC "Cannonano wine of Sardinia" with sub-names, Oliena, Nepente of Oliena, Capo Ferrato, and is blended in the AOC Mandrolisai or used for table wines and IGT wines.

\section{Discussion and conclusion}

The today shape of the Sardinian landscape is the result of the long lasting relations between natural conditions and the human activity, including history of people and zones. Areas today denser of wines and vineyards are those through which viticulture entered the island. Considering the socio-cultural perspective of the winelandscape, as a product of the relations between viticulture and the collective identity, can explain the persistency of viticulture and wine economy in principal vinegrowing areas, with respect to the considered grape-type in Sardinia, Vermentino and the Cannonao. These grapes are actually the expression of two historic, cultural and economic identities, then of two diverse local economies, continuously changing over time.

The higher diffusion of Vermentino in the tourist zone of Sardinia testimony the capabilities of local communities to integrate the vine-growing in a economic good flow, fostered by the tourist development [3]. This is quite true both for the AOC Vermentino of Alghero and the GAOC Vermentino of Gallura.

In the same line, the spatial concentration of Cannonao in the two homogeneous areas of Jerzu-Mandrolisai and Dorgali, located along the eastern Sardinian dorsal and separated by the Gulf of Orosei, is a direct consequence of the history of local people and settlements. The traditional viticulture continued over time until today for both environmental and social reasons. The local communities conserve a traditional vision of the conservation of the environment and an extreme sense belonging to places. The conservative aptitude of people, from one hand, ensured the conservation of near not altered landscapes, and, from another hand, put under risk the entire local viticulture due to the lacking of demand oriented productions, less alcoholic, especially for the Cannonao of Jerzu.

We like to give another notation on the resistance and concentration of viticulture in selected zones. Yet, this is to be found in the relations within the productionprocessing-distribution chain. Indeed, it is well known that the depletion of both quantitative production and cooperative wineries from the seventies until up today. It is likely due to the failure of integration of phases along the production chain $[2,3,6]$. The UE incentive for the uprooting of vineyards in the eighties must not be an excuse. The abandonment of vineyards and the missing transmission of grapes to the cooperative wineries from the associated vine-growers caused the ceasing of many cooperative wineries is to be interpreted as the inefficiency of the wine production system. Today, when cooperation is persisting and well working that is due to the organizing efficiency, actually market oriented.

\section{References}

[1] G.L. Corinto, Wine terroir concept: some preceding in Arrigo Serpieri's agrarian zone, (Enometrica, 1, 2011)

[2] G. Benedetto, Agroalimentare in Sardegna, struttura, competitività e decisioni imprenditoriali, (TAS, Sassari 1996)

[3] L. Idda, G. Benedetto and P. Pulina, Sviluppo rurale, capitale sociale e vitivinicoltura multifunzionale, 73 (Franco Angeli, Milano, 2007)

[4] L. Idda, G. Benedetto e F.A. Madau, Sviluppo rurale, capitale sociale e vitivinicoltura multifunzionale, 21 (Franco Angeli, Milano, 2007)

[5] ISTAT, Censimenti Generali dell'Agricoltura (vari anni)

[6] F. Nuvoli and G. Benedetto, Storia regionale della vite e del vino in Italia, 219 (Accademia Italiana della Vite e del Vino, Il Guado, Milano, 2003)

[7] L. Idda, G. Benedetto and R. Furesi, Marketing Agroalimentare, 117 (Franco Angeli, Milano, 2004)

[8] L. Idda, G. Benedetto and F.A. Madau, Sviluppo rurale, capitale sociale e vitivinicoltura multifunzionale, 91 (Franco Angeli, Milano, 2007)

[9] D. Carboni and S. Ginesu, Geography and landscape of wine in Sardinia, Espacio y Tiempo, Revista de Ciencias Humanas, 21 41-64 (2007)

[10] G. Mattioli, Monti e la sua Cantina, (Il Torchietto, Ozieri, 1996)

[11] M. Fregoni, Le Terre del Vermentino, vertourmer.com. (accesso del 4 settembre 2014)

[12] A. Lepori, La Sardegna ed il vino, (Artigiana ed., Cagliari, 2003) 